\title{
Erratum
}

\section{Western blot analysis of cerebrospinal fluid for detection of Aspergillus antigens}

\section{Pallab Ray, Arunaloke Chakrabarti, Manu Jatana, B. S. Sharma ${ }^{1}$ \& A. Pathak ${ }^{1}$}

Department of Medical Microbiology and Neurolsurgery ${ }^{1}$, Postgraduate Institute of Medical Education and Research, Chandigarh-160012, India

Mycopathologia 133: 103-106, 1995.

The line diagram which should be depicted in fig. 1(B) was inadvertently omitted. It shows the positive findings seen in the Western-blot analysis of fig. 1(A). 